\title{
Mouse model of the human serotonin transporter-linked polymorphic region
}

\author{
Lukasz Piszczek $^{1,2}$ (1) $\cdot$ Simone Memoli ${ }^{1}$ Angelo Raggioli ${ }^{1}$. José Viosca ${ }^{1,3}$ • Jeanette Rientjes ${ }^{4}$. Philip Hublitz ${ }^{1,5}$. \\ Weronika Czaban ${ }^{1} \cdot$ Anna Wyrzykowska ${ }^{1}$. Cornelius Gross ${ }^{1}$
}

Received: 21 February 2019 / Accepted: 21 September 2019 / Published online: 22 November 2019

(C) The Author(s) 2019

\begin{abstract}
Genetic factors play a significant role in risk for mood and anxiety disorders. Polymorphisms in genes that regulate the brain monoamine systems, such as catabolic enzymes and transporters, are attractive candidates for being risk factors for emotional disorders given the weight of evidence implicating monoamines involvement in these conditions. Several common genetic variants have been identified in the human serotonin transporter (5-HTT) gene, including a repetitive sequence located in the promoter region of the locus called the serotonin transporter-linked polymorphic region (5-HTT-LPR). This polymorphism has been associated with a number of mental traits in both humans and primates, including depression, neuroticism, and harm avoidance. Some, but not all, studies found a link between the polymorphism and 5-HTT levels, leaving open the question of whether the polymorphism affects risk for mental traits via changes in 5-HTT expression. To investigate the impact of the polymorphism on gene expression, serotonin homeostasis, and behavioral traits, we set out to develop a mouse model of the human 5-HTT-LPR. Here we describe the creation and characterization of a set of mouse lines with single-copy human transgenes carrying the short and long 5-HTT-LPR variants. Although we were not able to detect differences in expression between the short and long variants, we encountered several technical issues concerning the design of our humanized mice that are likely to have influenced our findings. Our study serves as a cautionary note for future studies aimed at studying human transgene regulation in the context of the living mouse.
\end{abstract}

Keywords 5-HTT $\cdot 5$-HTT-LPR $\cdot$ Serotonin $\cdot$ Mouse models

Electronic supplementary material The online version of this article (https://doi.org/10.1007/s00335-019-09815-2) contains supplementary material, which is available to authorized users.

Lukasz Piszczek and Simone Memoli have contributed equally to this work.

Lukasz Piszczek

lukasz.piszczek@imp.ac.at

Cornelius Gross

gross@embl.it

1 Epigenetics and Neurobiology Unit, European Molecular Biology Laboratory, EMBL Rome, Monterotondo, Italy

2 Present Address: Research Institute of Molecular Pathology, Vienna, Austria

\section{Introduction}

Disturbances in the serotonin (5-hydroxytryptamine, 5-HT) system have been implicated in the pathophysiology of a wide variety of mental disorders, including anxiety, depression, aggression, addiction, and suicide. The serotonin transporter (5-HTT, SLC6A4) regulates the spatio-temporal fine-tuning of 5-HT signaling by mediating the re-uptake of serotonin from the synaptic cleft. Drugs that block 5-HTT prolong the synaptic lifetime of serotonin and boost the

3 Present Address: Promotion of Health and Biomedical Research in the Valencian Region (FISABIO), Valencia, Spain

4 Monash Genome Modification Platform (MGMP), Monash University, Clayton, Australia

5 MRC Weatherall Institute of Molecular Medicine, University of Oxford, Oxford, UK 
activation of its receptor targets are effective antidepressants. At the same time, genetic variants in 5-HTT that reduce its expression or functionality are associated with increased risk for mood disorders and its associated traits (Malison et al. 1998; Little et al. 1998; Purselle and Nemeroff 2003). The apparent opposite effects of pharmacological and genetic loss-of-function manipulations of 5-HTT remain unexplained, but have been proposed to depend either on the engagement of negative feedback mechanisms on serotonin neuron firing triggered by acute pharmacological inhibition or on the impact of genetic variations on brain developmental trajectories (Ansorge et al. 2004; Homberg et al. 2010; Oh et al. 2009; Popa et al. 2008).

Several common genetic variants have been identified in the human 5-HTT gene. Of these, the most extensively studied is a polymorphic repetitive sequence located upstream of the transcription start site called the serotonin transporterlinked polymorphic region (5-HTT-LPR; Lesch et al. 1997; Murphy et al. 2004). This promoter region is composed of repetitive nucleotide sequences each 20 to 23 base pairs long, with the most frequent alleles called the "short" allele (S), containing 14 repeats, and the "long" allele (L), containing 16 repeats (Lesch et al. 1997; Colucci et al. 2008). The most common sub-variant of the $\mathrm{L}$ allele is called 16A, while that of the $\mathrm{S}$ allele is called 14A (Nakamura et al. 2000). Interestingly, the frequency of the 5-HTT S and L variants differs significantly across human populations (Noskova et al. 2008). Moreover, the 5-HTT-LPR is only present in humans and higher primates, but not in prosimians and rodents (Lesch et al. 1997). The lack of a suitable mouse model of 5-HTT-LPR has hampered the understanding of its molecular, cellular, and physiological impact on mental traits.

Several studies found a link between the 5-HTT-LPR $\mathrm{S}$ allele, the presence of environmental adversity, and increased risk for major depression. Individuals homozygous for the $\mathrm{S}$ allele of the polymorphism were more susceptible to the negative effects of life stressors in early childhood than those homozygous for the $\mathrm{L}$ allele, resulting in an increased risk for major depression (Caspi et al. 2003; Kaufman et al. 2004; Kendler et al. 2005, but see Munafò et al. 2008 and Risch et al. 2009). In the absence of identifiable stress events no increased risk for depression was observed, suggesting that the major mechanisms by which 5-HTT-LPR moderates mental traits may be via its effect on the impact of environmental stressors. Nevertheless, some studies that did not quantify environmental stressors did find increased anxiety-related personality traits in S allele carriers, including increased neuroticism and harm avoidance (Lesch et al. 1996; Greenberg et al. 2000). Moreover, several studies have shown differences in $\mathrm{S}$ allele carriers in steadystate and event-related neural activity in cortex and amygdala as measured by functional magnetic resonance imaging
(fMRI), a finding that was more pronounced in depressed subjects (Hariri and Holmes 2006; Canli et al. 2005; Heinz et al. 2005; Dannlowski et al. 2007; Lau et al. 2009; Pezawas et al. 2005).

Although some data demonstrate that the 5-HTT-LPR S allele is associated with reduced expression of the 5-HTT gene in human lymphocytes (Lesch et al. 1996; Heils et al. 1996; Hranilovic et al. 2004; Lima et al. 2005), the magnitude, direction, and time course of this effect in the human brain remains unclear. Positron emission tomography (PET) imaging studies in the living brain have shown a correlation between the $\mathrm{S}$ allele and decreased 5-HTT ligand binding levels (Reimold et al. 2007), however, others reported no such correlation (Parsey et al. 2006; Shioe et al. 2003). Together, these studies suggest that the effect of 5-HTT-LPR on gene expression may be cell-type and/or time-dependent, with greater differences possibly occurring at early developmental stages. Such an effect would be consistent with animal studies in which pharmacological blockade of 5-HTT during the first postnatal weeks is sufficient to alter anxietyrelated behavior measured later in adulthood (Ansorge et al. 2004).

To facilitate the study of the molecular, cellular, and physiological consequences of 5-HTT-LPR variants, we developed a set of transgenic mouse lines carrying the human 5-HTT locus with either the 5-HTT-LPR-16A (L, long) or 14A (S, short) alleles. Variants were introduced into the human 5-HTT locus into a bacterial artificial chromosome (BAC) using recombineering in bacteria. The inclusion of both fluorescence and luciferase reporter genes into the 5-HTT gene open reading frame facilitated the assessment of transgene spatial expression and quantitative comparison at low expression levels, respectively. To allow for direct comparisons of $\mathrm{S}$ and $\mathrm{L}$ allele function in mouse, we inserted the human 5-HTT locus at the same position in each line using recombination-mediated cassette exchange (RMCE). Here we present data describing the expression of the $\mathrm{S}$ and $\mathrm{L}$ variant human transgenes in mouse.

\section{Materials and methods}

\section{Targeting constructs}

The FRT-PGK-em7-Keo-FRT cassette was amplified using high-fidelity PCR from pPKG-em7-Keo-FRT and used for TOPO TA cloning into the pCRII plasmid (TOPO TA Cloning Kit Dual Promoter, Invitrogen). SYFP2 coding sequence (from pSYFP2-C1, Kremers et al. 2006) was amplified via high-fidelity PCR and inserted in-frame along with a firefly luciferase coding sequence (amplified from psiCHECK-2, Promega) with a P2A sequence (Holst et al. 2006) upstream 
of the firefly luciferase gene. The ends of a human BAC (RP11-126E3, Chori BACPAC Resources) containing a genomic fragment harboring the entire coding region of the 5 -HTT gene (SLC6A4) was trimmed using bacterial recombineering to produce a $62 \mathrm{~kb}$ fragment starting at the end of the flanking BLMH gene and ending at the stop of the CCDC55 gene. The resulting P2A-hLuc-T2A-SYFP-FRTPGK-Em7-Keo-FRT construct was then inserted to replace the stop codon of the trimmed human BAC (clone 11A6) by recombineering, resulting in RP11-126E3/P2A-hLuc-T2ASYFP-FKF, called RP11-16A for short.

Several attempts at using bacterial recombineering with negative selection (SacB or Rpsl; Muyrers et al. 1999, 2000; Heermann et al. 2008) to convert RP11-16A into RP11-14A without altering the surrounding sequence failed because positive clones invariably carried large deletions of the BAC and we decided to use recombineering with positive selection followed by removal of the selectable marker via flanking rox recombinase sites. First, a 16A-Rox BAC was constructed by recombining a rox-Zeo-rox cassette into RP11-16A 116 bp upstream of 5-HTT-LPR, after which the Zeo cassette was removed by Dre-mediated excision. Next, a 14A-Rox construct was created by recombineering the rox-Zeo-rox cassette into the previously created pBSK-14A plasmid containing the 14A sequence from the human RP11-104B7 BAC (Chori BACPAC Resources). Finally, the resulting product was used for recombining it into the previously created RP11-AMP BAC to exchange the AMP-SacB cassette and produce RP11-14A-rox-Zeo-rox. Ultimately, the Zeo cassette was removed by Dre-mediated excision to create RP11-14A-rox. The sequence of the modified human promoter as well as modified 3' end of the 5-HTT has been provided as Supplementary Data. The sequence of the entire targeting constructs is available upon request.

\section{Cell line targeting}

The RMCE acceptor ES cell line (CGL1.10E; 129S7 genetic background) was kindly provided by Haydn Prosser (Sanger Institute, Hinxton, UK). ES cells were cultivated on mitomycin C treated SNL Feeder Cells (kindly provided by Haydn Prosser). The targeting protocol was adapted from a previous published method for RMCE (Prosser et al. 2008). Briefly, 10.5 million trypsinized cells were mixed with $10 \mu \mathrm{g}$ of $\mathrm{CsCl}$ purified $\mathrm{BAC}$ and $25 \mu \mathrm{g}$ of pCAGGS-Cre (kindly provided by Olga Ermakova, CNR) in a $0.4 \mu \mathrm{m}$ cuvette (Bio$\mathrm{Rad})$ and electroporated $(230 \mathrm{~V}, 500 \mu \mathrm{F})$. Cells were collected, centrifuged ( $5 \mathrm{~min}, 1000 \mathrm{rpm}$ ) and plated on a $10 \mathrm{~cm}$ dish. Four to five such electroporations were performed per construct to ensure the recovery of sufficient number of positive clones. After $24 \mathrm{~h}, 200 \mu \mathrm{g} / \mathrm{ml} \mathrm{G} 418$ (Invitrogen) was added to the medium and the selection continued for 2-3 days, after which $10 \mu \mathrm{M}$ 6-TG (6-thioguanine or 2-amino-6-mercaptopurine, Sigma-Aldrich) with $200 \mu \mathrm{g} / \mathrm{ml}$ G418 selection was carried out for an additional 6-8 days. Resistant clones were picked in a SNL-seeded 96-well plates and frozen down after reaching confluence. During the picking of clones a replica plate with $0.1 \%$ gelatin-coated wells was prepared for Southern Blot screening. For blastocyst injection positive clones were thawed onto a 48 -well plate, passaged on 12-well plates, and expanded on 6-well plates before transfer on ice to the EMBL Transgenic Facility.

\section{Mouse lines}

Generated 5-HTT-LPR chimeras were crossed for one generation onto 129S5 (129/SvEvBrd, kindly provided by Allan Bradley) background (Ermakova et al. 2011) to obtain the lines germline transmission. In a subsequent step all lines were crossed to the Rosa26::FlpO line (129 Sv S4/S5) to delete the selection cassette and backcrossed to 129S5 for one generation. Obtained lines were maintained on mixed 129 Sv background (16-A line: $129 \mathrm{~Sv}-R_{\text {Rosa }} 6^{\mathrm{tm} 16-\mathrm{A}-5-\mathrm{HTT} /+}$; 16-A rox line: $129 \mathrm{~Sv}-R_{0} a 26^{\mathrm{m} 16-\mathrm{A} \text { rox-5-HTT/+}}$; 16-A rox line: $\left.129 \mathrm{~Sv}-\operatorname{Rosa}_{2} 6^{\mathrm{tm} 14-\mathrm{A} \text { rox-5-HTT/+}}\right)$.

The generation and characterization of the Tph2::rLuc

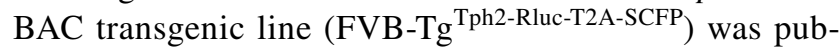
lished elsewhere (Mlinar et al. 2016). This line was induced and maintained on an inbred $\mathrm{FVB} / \mathrm{J}$ genetic background, crossed to the created 5-HTT-LPR lines for testing on an F1 hybrid genetic background.

\section{Animal husbandry}

Animals were housed in groups of two to four per cage with free access to food and water. Animals were maintained on a 12:12 light/dark schedule (lights on at 7:00, off at 19:00). All mice were handled according to protocols approved by the Italian Ministry of Health (\#137/2011-B, \#231/2011-B, \#541/2015-PR) and commensurate with NIH guidelines for the ethical treatment of animal.

\section{Southern blot}

Mouse embryonic stem cells (ES) were grown to confluency, washed twice with 1 XPBS and lysed in buffer $(10 \mathrm{mM}$ Tris pH 7.5, $10 \mathrm{mM}$ EDTA, $10 \mathrm{mM} \mathrm{NaCl}, 0.5 \%$ sarcosyl, $1 \mathrm{mg} /$ $\mathrm{ml}$ Proteinase K). The plate was incubated at $56{ }^{\circ} \mathrm{C}$ overnight in a humid atmosphere. DNA was ethanol-precipitated and resuspended in digestion buffer $(1 \times$ restriction buffer, $1 \mathrm{mM}$ spermidine, $1 \mathrm{mM}$ DTT, $100 \mu \mathrm{g} / \mathrm{ml} \mathrm{BSA}, 50 \mu \mathrm{g} / \mathrm{ml}$ RNse A, 50-80 U EcoRI enzyme). The plate was incubated overnight at $37{ }^{\circ} \mathrm{C}$ in a humid atmosphere. The following day, DNA digest products were resolved by electrophoresis and DNA was transferred according to standard protocol (Southern 2006) in alkaline solution $(0.4 \mathrm{M} \mathrm{NaOH}, 1.5 \mathrm{M} \mathrm{NaCl})$ onto a nylon 
membrane (Hybond-N +, Amersham). After transfer, the membrane was washed $3 \times 15 \mathrm{~min}$ in $2 \mathrm{xSSC}$, air-dried for $1 \mathrm{~h}$ and cross-linked (150 mJ, UV-Crosslinker, Vilber Lourmat). Southern blot was performed in hybridization buffer $(0.5 \mathrm{M}$ Phosphate Buffer, $1 \mathrm{mM}$ EDTA, 3\% BSA, 5\% SDS) with $25 \mathrm{ng}$ of radioactively labeled probe ([$\alpha-32 \mathrm{P}]-\mathrm{dGTP}$, PerkinElmer) according to manufacturer instructions (Random Primers DNA Labeling System, Invitrogen). After $3 \times 30$ min washing steps (40 mM Phosphate Buffer, $1 \mathrm{mM}$ EDTA, 5\% SDS) the membrane was exposed to a phosphoscreen (BAS-IP SR2040, Fujifilm) and developed after $24 \mathrm{~h}$ (FLA 5100R, Fujifilm). The Southern probe used for screening resistant clones after RMCE was kindly provided by Haydn Prosser. The probe mapped external to the targeting construct (ROSA26 gene locus) was $400 \mathrm{bp}$ in size. It was excised using KpnI/BglII, gel-purified, and $25 \mathrm{ng}$ used for labeling and Southern blot screening.

\section{PCR-based screen}

Human-specific primer pairs used for validating the human BAC constructs and screening positive ES clones after RMCE were designed using Primer-BLAST (www.ncbi. nlm.nih.gov/tools/primer-blast/). The PCR conditions used were as follows: $1 \times$ DreamTaq Green Buffer (supplied as $10 \times$ stock by manufacturer, Fermentas $\mathrm{GmbH}$, Germany), $0.2 \mathrm{mM}$ dNTPs, $0.8 \mu \mathrm{g} / \mu \mathrm{l}$ BSA, $1 \mu \mathrm{M}$ of each primer, 0.05 U/ $\mu 1$ DreamTaq Polymerase, and either $150 \mathrm{ng}$ BAC or $300 \mu \mathrm{g}$ genomic template DNA. In most cases the genomic DNA had to be digested by EcoRI, EcoRV, KpnI or ScaI restriction enzymes before being used as a successful template for PCR reaction. PCR conditions were: $95{ }^{\circ} \mathrm{C}$ for 3 min, 45 cycles at $95{ }^{\circ} \mathrm{C}$ for $30 \mathrm{~s}, 60^{\circ} \mathrm{C}$ for $30 \mathrm{~s}, 72^{\circ} \mathrm{C}$ for $210 \mathrm{~s}$, and 1 cycle of $72{ }^{\circ} \mathrm{C}$ for $10 \mathrm{~min}$. The primer sequence list is provided in Supplementary Table 1.

\section{Mouse lines genotyping}

Tail tissue fragments (stored at $-20{ }^{\circ} \mathrm{C}$ ) were thawed at RT, digested in $200 \mu \mathrm{L}$ of digest buffer $(50 \mathrm{mM}$ Tris- $\mathrm{HCl}, \mathrm{pH}$ 8.0; $1 \mathrm{mM}$ EDTA, pH 8.0; $20 \mathrm{mM} \mathrm{NaCl} ; 1 \%$ SDS; $1 \mathrm{mg} / \mathrm{mL}$ proteinase $\mathrm{K}$ ) and incubated at $56{ }^{\circ} \mathrm{C}$ overnight. Digests were removed from the heat, spun down (10 min, $14 \mathrm{k} \mathrm{rpm})$, and $150 \mu \mathrm{L}$ of supernatant were collected into a fresh tube. 150 $\mu \mathrm{L}$ isopropanol were added to each tube, vortex and centrifuged (20 min, $14 \mathrm{k} \mathrm{rpm}$ ). Supernatant was gently discarded and the pellet was washed with $150 \mu \mathrm{L}$ of $70 \% \mathrm{EtOH}$ and centrifuged (20 min, $14 \mathrm{k} \mathrm{rpm}$ ). Supernatant was removed and pellet was dried at RT for $10 \mathrm{~min}$. Precipitated DNA was resuspended in $20 \mu \mathrm{L}$ of double-distilled sterile $\mathrm{H}_{2} \mathrm{O}$ $1.5 \mu \mathrm{L}$ were added to $24 \mu \mathrm{L}$ of PCR reaction buffer $(0.2 \mathrm{mM}$ dNTPs; 10 mM Tris-HCl, pH 9.0; 50 mM KHCl; $1.5 \mathrm{mM}$ $\mathrm{MgCl}_{2} ; 0.1 \mathrm{mg} / \mathrm{mL} \mathrm{BSA} ; 1 \mu \mathrm{M}$ of each genotyping primer; $0.04 \mathrm{U} / \mu \mathrm{L}$ Taq Polymerase). PCR products were resolved by electrophoresis on 2-3\% agarose gels [in TAE (Tris-Acetate-EDTA) buffer with $0.5 \mu \mathrm{g} / \mathrm{mL}$ ethidium bromide, ran at $130 \mathrm{~V}$ (constant current). PCR primer used for genotyping for the 5-HTT-LPR lines were: RMCE-forward 5'-TTGCTT TTTGTGTAGCTGACC-3'; WT-forward 5'-GCACTTGCT CTCCCAAAGTC-3'; WT-reverse 5'-CCGAAAATCTGT GGGAAGTC-3'; giving 336 bp product for WT allele, and $626 \mathrm{bp}$ for targeted one. Genotyping of the Tph2::rLuc were done using: Forward 5'-CCATCTCTTCCCAAAGAGCT-3'; Reversed 1 5'-GTTCATTTGCTTGCAGCGAG-3'; Reversed 2 5'-CAACTCGCCCAGCTGCTTGT-3'; giving 607 bp product for WT allele, and $416 \mathrm{bp}$ for targeted one. The PCR conditions were $95{ }^{\circ} \mathrm{C}$ for $2 \mathrm{~min}, 2$ cycles at $95^{\circ} \mathrm{C}$ for $15 \mathrm{~s}, 64^{\circ} \mathrm{C}$ for $15 \mathrm{~s}, 72^{\circ} \mathrm{C}$ for $90 \mathrm{~s}, 2$ cycles at $95^{\circ} \mathrm{C}$ for $15 \mathrm{~s}, 61^{\circ} \mathrm{C}$ for $15 \mathrm{~s}, 72{ }^{\circ} \mathrm{C}$ for $90 \mathrm{~s}, 20$ cycles at $95^{\circ} \mathrm{C}$ for $15 \mathrm{~s}, 58^{\circ} \mathrm{C}$ for $15 \mathrm{~s}, 72^{\circ} \mathrm{C}$ for $90 \mathrm{~s}, 14$ cycles at $95^{\circ} \mathrm{C}$ for $15 \mathrm{~s}, 55^{\circ} \mathrm{C}$ for $15 \mathrm{~s}, 72^{\circ} \mathrm{C}$ for $90 \mathrm{~s}$, and 1 cycle of $72^{\circ} \mathrm{C}$ for $10 \mathrm{~min}$.

\section{Immunofluorescence}

Mice were anesthetized intraperitoneally with Avertin (Sigma-Aldrich) and perfused transcardially with $4 \%$ paraformaldehyde. Brains were post-fixed overnight at $4{ }^{\circ} \mathrm{C}$, cryoprotected in $30 \%$ sucrose, and frozen on dry ice. $40 \mu \mathrm{m}$ sections were collected using a cryostat and stained with primary antibody overnight at $4{ }^{\circ} \mathrm{C}(1: 1000$ rabbit $\alpha$-GFP, Life Technologies) and incubated with secondary antibodies ( $2 \mathrm{~h}$ at room temperature, goat IgG A647, Molecular Probes/ Invitrogen) and DAPI. Confocal microscopy was performed with a TCS-SP5 Leica Laser Scanning System. The images were processed using ImageJ software (NIH).

\section{Protein extraction and luciferase assays}

After perfusion with saline fresh brains were frozen on dry ice and stored at $-80^{\circ} \mathrm{C}$. For protein extraction, the whole brain of postnatal day 6 (P6) animals or dorsal raphe tissue punches (adult animals) were homogenized with Passive Lysis Buffer (Promega) and proteinase inhibitors (cOmplete ULTRA Tablets, Mini, EDTA-free, EASYpack, Roche) using an electrical homogenizer (POLYTRON PT 1200 E Manual Disperser, Kinematica). Tissue was further disrupted using a syringe and pipetting. The whole procedure was performed on ice. Samples were then shaken in a thermomixer at $1000 \mathrm{rpm}$ and $4{ }^{\circ} \mathrm{C}$ in a cold room for $1 \mathrm{~h}$, centrifuged, and supernatant collected. Samples were stored at $-80{ }^{\circ} \mathrm{C}$ until assaying. Luciferase assays (Firefly and Renilla) were done on the protein extracts according to manufacturer instructions (Dual-Luciferase Reporter Assay System, Promega). The signal was normalized to the amount of protein in the sample as determined by Pierce BCA Protein Assay Kit (Thermo Fisher Scientific) according to manufacturer instructions. 


\section{Statistical analysis}

In general, analysis of luciferase signal was performed using Prism4 software (GraphPad). The effect of genotype and sex was assessed by two-way ANOVA. In case of significance ANOVA was followed by Tukey's multiple comparison post hoc test to compare individual genotypes.

\section{Results}

\section{5-HTT-LPR-16A line creation and analysis}

We took advantage of recombination-mediated cassette exchange (RMCE; Prosser et al. 2008) at the mouse Rosa26 gene locus to create mouse lines harboring a single-copy insertion of the human 5-HTT gene locus with either the $\mathrm{S}$ or $\mathrm{L}$ promoter variant and carrying cistrons expressing both fluorescent and luciferase reporter proteins (Fig. 1a). We used recombineering to truncate a 5-HTTcontaining human bacterial artificial chromosome (BAC) to include a $62 \mathrm{~kb}$ region containing the $5-H T T$ gene, insert a neomycin selection cassette into the backbone, and add yellow fluorescent (YFP) and firefly luciferase (fLuc) protein open reading frames at the stop codon of the human 5-HTT via viral-derived 2A self-cleaving protein linkers (see "Materials and Methods"). The sequence of the inserted BAC was confirmed to be identical to the mouse reference sequence using Solexa deep sequencing (Supplementary Fig. 1). PCR of the 5-HTT-LPR region identified a human BAC contained the long, 16A polymorphism. Co-electroporation of the modified BAC with a

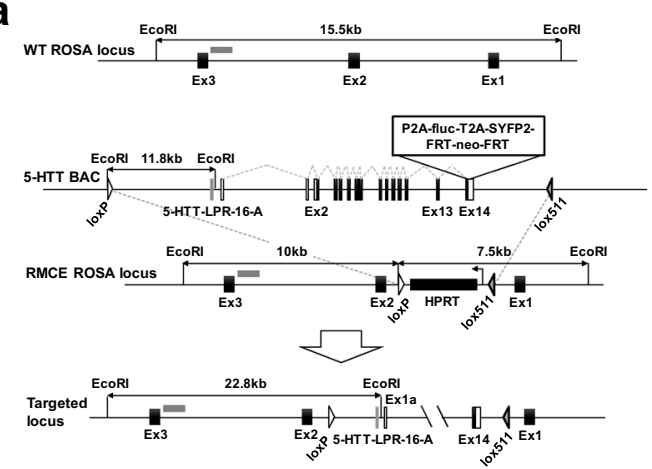

b

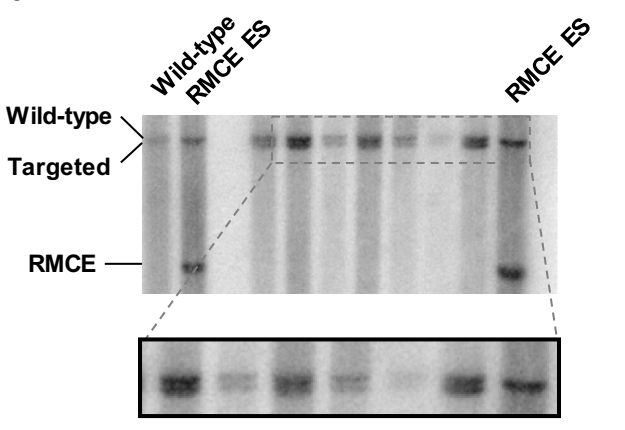

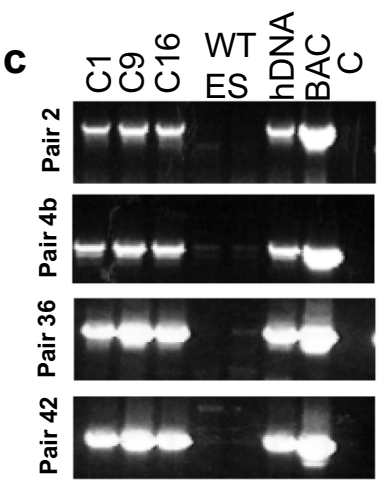

$\mathbf{f}$

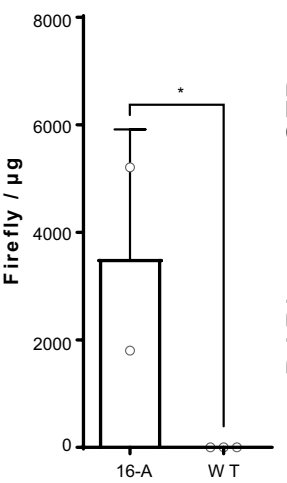

$16-\mathrm{A}$

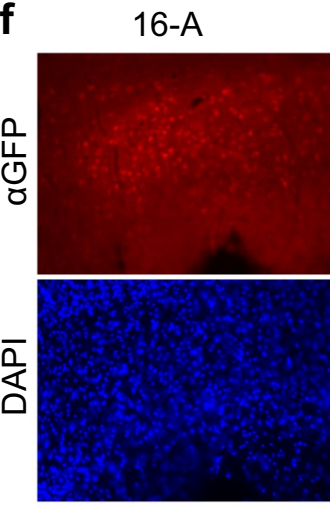

Wild-type

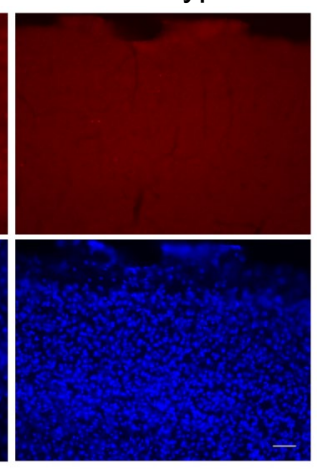

Fig. 1 Generation of a mouse line carrying a single-copy human 5-HTT transgene. a-c The targeting vector was obtained by inserting a P2A-hLuc-T2A-SYFP2-FRT-Neo-FRT cassette at the stop codon of the human 5-HTT gene within a $62 \mathrm{~kb}$ human genomic fragment (BAC). Cre/LoxP recombination-mediated cassette exchange (RMCE) was then used to insert a single copy of the targeting vector into an acceptor site engineered at the Rosa26 in mouse ES cells. Proper ES cell targeting was verified by Southern Blot (b) transgene integrity was confirmed using a set of overlapping PCR probes spanning the region (c). d Expression of the human 5-HTT in the mouse brain as detected by the distribution of SYFP immunofluorescence in coronal brain sections from 5-HTT-LPR-16A mice $(n=2)$. Positive cell bodies are observed in the dorsal raphe nucleus (dashed line) and at lower levels outside the raphe in transgenic mice (intensity in the raphe is $40 \%$ higher). Background staining is seen in littermate wild-type (WT) controls. Scale bar: $200 \mu \mathrm{m}$. e Luciferase assays on adult whole brain protein extracts confirmed transgene expression in 16A $(n=2)$, but not WT controls $(n=3$; data shown as mean $\pm \mathrm{SD})$. f Ectopic expression of the human 5-HTT in the mouse brain as detected by the distribution of SYFP immunofluorescence in coronal brain sections from 5-HTT-LPR-16A observed in the cortex (scale bar: $50 \mu \mathrm{m})$ 
a Cre recombinase expressing plasmid (pCAGGS-Cre) allowed for the neomycin-resistance selection of RMCEmediated insertion of the BAC into the mouse genome in an ES cell line engineered to carry LoxP and Lox511 sites at the Rosa26 locus (Prosser et al. 2008). Selection and purification identified several ES cell clones carrying the modified human 5-HTT locus correctly inserted at the mouse Rosa26 locus as detected by Southern blot (Fig. 1b). RMCE has been used reliably to introduce large single-copy genomic sequences of both human (Wallace et al. 2007; Vernimmen et al. 2009) and murine (Prosser et al. 2008) origin at specific genomic locations. However, it should be noted that there is some chance, albeit arguably very low, of multiple inserts of our construct into the murine genome. Nevertheless, stronger limitation for applying this technique is the fact that a third of positive clones contained inversions and/or deletions in the targeting construct that could not be detected by a standard Southern blot analysis (Prosser et al. 2008). To address this concern we employed an extensive, PCR-based screen. Therefore, the integrity of the successfully targeted allele was confirmed by performing numeral PCR assays on mouse genomic DNA from tail biopsy with a set of 44 human-specific primer pairs tiling the BAC at 100-500 bp intervals. Electrophoretic analysis of the resulting products allowed us to exclude several positive clones carrying large deletions (data not shown, Fig. 1c). Confirmed ES clones were then injected into mouse blastocysts to obtain chimeric offspring with at least one of them demonstrating germline transmission of the human 5-HTT-LPR-16A transgene. Analysis of brains of heterozygous transgene positive offspring revealed expression of YFP in sections from the dorsal raphe (Fig. 1d) as well as expression of firefly luciferase activity in tissue punches from the same region (Fig. 1e; one-tailed $t$ test, $t_{(3)}=2.758, p=0.035$ as compared to wild-type animals).

\section{5-HTT-LPR-16A/14A-Rox lines creation and analysis}

To determine the effect of the 5-HTT-LPR polymorphism on the expression of 5-HTT we constructed a mouse line in which the 16A sequence was mutated to 14A. Unfortunately, several bacterial recombineering strategies were unsuccessful at replacing the $16 \mathrm{~A}$ variant by the $14 \mathrm{~A}$ variant without modifying the surrounding genomic DNA (see "Materials and Methods"). Instead, we settled on a two-step, positive/ negative selection recombineering technique (Muyrers et al. 2000) in which we first replaced the 5-HTT-LPR in our 16A modified human BAC with an AMP-SacB negative selection cassette. Next, we introduced a Zeomycin (Zeo) positive selection gene flanked by rox site specific recombinase recognition sites (Anastassiadis et al. 2009) upstream of the $14 \mathrm{~A}$ variant within a smaller targeting plasmid and used recombineering to replace AMP-SacB within the larger trimmed human BAC with the 5-HTT-LPR-14A sequence. Finally, the Zeo-selection gene was removed by Dremediated excision leaving behind a $32 \mathrm{bp}$ rox site $116 \mathrm{bp}$ upstream of 5-HTT-LPR (Fig. 2a). In parallel, we introduced a

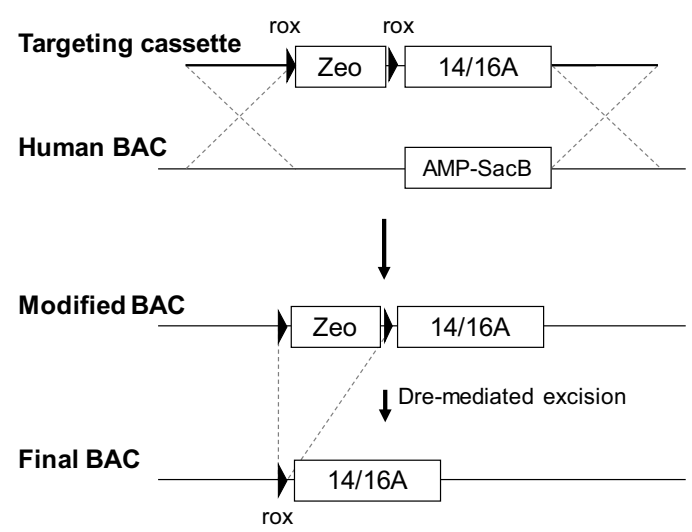

b

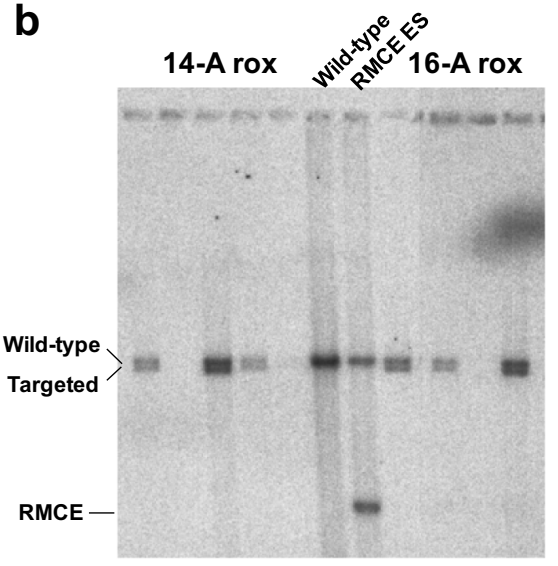

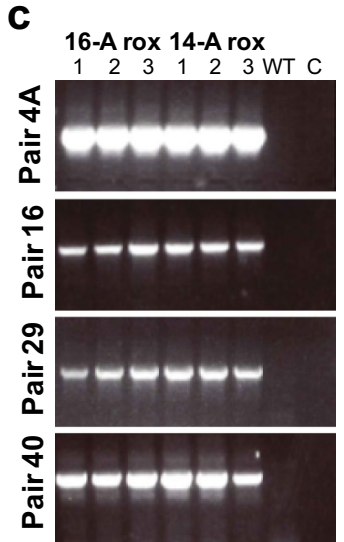

Fig. 2 Generation of 5-HTT-LPR-16A-Rox and 14A-Rox mouse lines. a Generation of mice bearing the rox 16-A/14-A human 5-HTT-LPR Short (14A) allele. Cassettes carrying either the 14A or $16 \mathrm{~A}$ polymorphisms with a rox-flanked Zeo-selection cassette inserted 116 bp upstream were used to replace the AMP-SacB cassette inserted into a 5-HTT-LPR containing BAC. Following selection of the correctly inserted polymorphic cassettes the Zeo-selection gene was removed by Dre-mediated recombination. This procedure left a 32 bp rox site upstream of 5-HTT-LPR. The 16A-Rox and 14A-
Rox constructs were separately targeted to a mouse Rosa26 acceptor locus using Cre-dependent RMCE to produce single-copy insertions of the human 5-HTT locus at the same mouse genome location. b, c Targeting of the Rosa26 acceptor locus via RMCE and Southern blot screening using a 3 ' radiolabeled probe. Positive ES clones were picked for expansion and further screening with the same PCR-based approach used to test transgene integrity above. Representative samples of 4 primer pairs are shown 
and excised identical Zeo cassette in the original 16A modified human BAC. This strategy resulted in the creation of two BAC constructs identical except for the 5-HTT-LPR 16A/14A site, but that differed from the endogenous human locus by the presence of the rox site. Both constructs were used for RMCE targeting in ES cells done in parallel, resulting in several positive clones as assessed by Southern blotting (Fig. 2b). The integrity of the BACs within the resulting ES cell lines was confirmed by the previously described nested PCR-method (Fig. 2c). Confirmed clones were then used to generate and establish two separate mouse lines for 5-HTT-LPR-16A and 14-A variants, the 16A-Rox and 14ARox lines respectively.

To determine whether the $16 \mathrm{~A}$ and $14 \mathrm{~A}$ variants were associated with differential expression of 5-HTT in the context of mouse brain development, we quantified firefly luciferase activity in brain samples taken from either postnatal day 6 (P6) pups or adults of both lines. Two-way ANOVA analysis revealed no main effect of genotype $\left(F_{1,25}=1.89\right.$, $p=0.181)$, but a significant main effect of $\operatorname{sex}\left(F_{1,25}=4.729\right.$, $p=0.039)$, and no interaction between the two $\left(F_{1,25}=0.392\right.$, $p=0.537$ ), suggesting that the 5-HTT-LPR polymorphism does not affect 5-HTT expression during development, at least as assessed by firefly luciferase activity at this developmental stage (Fig. 3a). In adult animals we were able to use tissue punches to reliably excise tissue from the dorsal raphe region of the brainstem where serotonin neurons have their cell bodies. To control for possible variation in the recovery of serotonin cell bodies within the excised tissue, we crossed the 16A-Rox and 14A-Rox lines to a Tph2::rLucSCFP transgenic mouse line in which Renilla luciferase is expressed selectively in serotonin neurons (Mlinar et al. 2016) and normalized our firefly luciferase measurements to Renilla luciferase within each sample. As expected, firefly luciferase activity was detected only in brain samples from mice carrying either 16A-Rox or 14A-Rox, but not in those carrying only Tph2::rLuc-SCFP (Supplementary Fig. 2a, one-way ANOVA. $F_{3,7}=36.36, p=0.0001$ followed by Tukey post hoc test). Conversely, Renilla luciferase activity was detected only in brain samples from mice carrying the Tph2::rLuc-SCFP transgene (Supplementary Fig. 2b, one-way ANOVA. $F_{3,7}=44.01, p<0.0001$, followed by Tukey post hoc test). Two-way ANOVA analysis of firefly luciferase activity in dorsal raphe tissue punches from adult double transgenic mice (Fig. 3b) showed no main effect of genotype $\left(F_{1,8}=0.8805, p=0.3755\right)$, sex $\left(F_{1,8}=0.9958\right.$, $p=0.3476)$, nor interaction between the two $\left(F_{1,8}=0.4039\right.$, $p=0.5428)$. Similarly, firefly luciferase activity normalized to Renilla luciferase signal (Fig. 3c) in another cohort of animals showed no main effect of genotype $\left(F_{1,26}=2.482\right.$, $p=0.127)$, sex $\left(F_{1,26}=1.613, p=0.215\right)$, nor interaction between the two $\left(F_{1,26}=2.342, p=0.138\right)$. These findings suggest that the 5-HTT-LPR polymorphism does not affect 5-HTT gene expression in either early postnatal development or adulthood in the mouse.

\section{Discussion}

Our findings are consistent with data suggesting that the 5-HTT-LPR polymorphism does not affect 5-HTT expression in adult human brain (Parsey et al. 2006; Shioe et al. 2003). However, several technical issues concerning our ability to faithfully model human gene expression in the mouse call into question this conclusion. First, although we were able to detect expression of the human 5-HTT gene from our BAC transgenic locus in the 16A line (Fig. 1e), we also detected low levels of ubiquitous transgene expression, additional to 5-HTT pattern (Fig. 1f) suggesting that either our transgenic construct is missing important human regulatory sequences or that the mouse host is missing critical transcription factors required to suppress ectopic expression

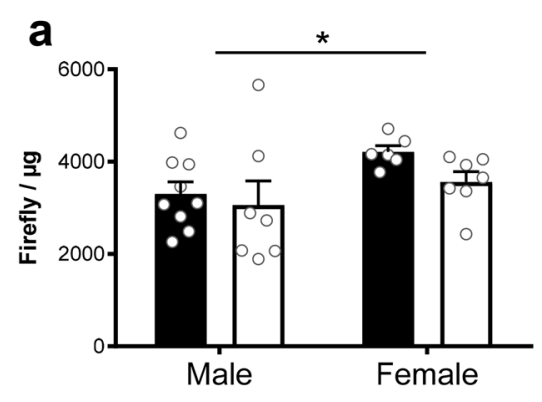

Fig. 3 Transgene expression in 16A-Rox and 14A-Rox lines. a Firefly luciferase activity in whole brain samples from 16A-Rox $(n=15$, 9 males, 6 females) and 14A-Rox $(n=14,7$ males, 7 females $)$ at postnatal day 6. No significant effect of genotype was detected, but female mice showed significantly greater transgene expression than males. b Luciferase activity in tissue punches from the dorsal raphe of adult (postnatal day 60) 16A-Rox;Tph2::rLuc-SCFP and
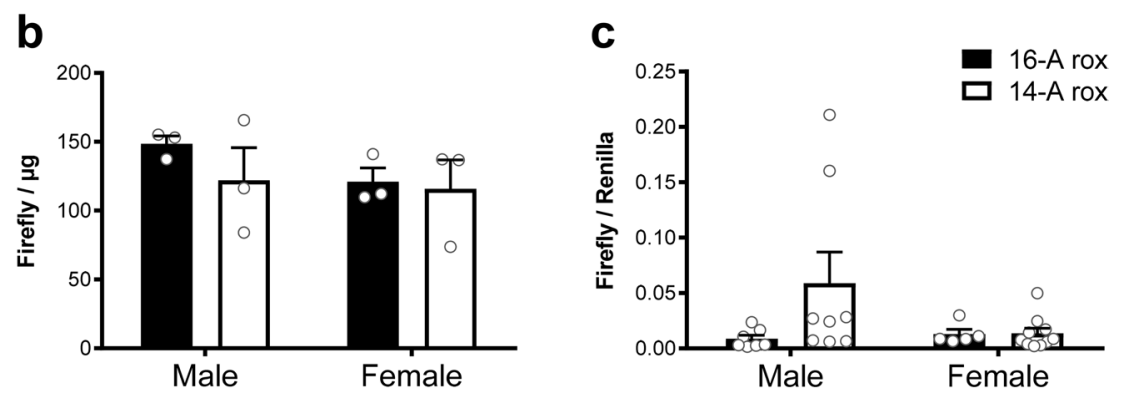

14A-Rox;Tph2::rLuc-SCFP mice revealed no significant genotype or sex effects (16A-Rox: $n=6,3$ males, 3 females; 14A-Rox: $n=6$, 3 males, 3 females). c Relative luciferase activity was used to control for potential inconsistencies in the recovery of serotonin cell bodies in the raphe tissue punches (16A-Rox: $n=12,7$ males, 5 females; and 14A-Rox: $n=19,8$ males, 11 females; data shown as mean \pm SEM) 
of the human locus. Another explanation that we cannot rule out at this point, is the genomic location of the transgene at Rosa 26 locus. However, the genomic transcription from the murine locus goes in the opposite direction to the human transgene. This makes it highly unlikely that the Rosa26 promoter is driving the low level, broad 5-HTT expression from our transgene, but cannot be excluded at this point. Furthermore, it is possible that these missing regulatory mechanisms are necessary for the polymorphism to impact gene expression. Second, our data suggest that the Rox site left upstream of the 5-HTT-LPR as a result of our recombineering strategy significantly interfered with expression of the human transgene. We were unable to detect SYFP in tissue sections from either 16A-Rox or 14A-Rox mice and absolute levels of luciferase activity from the Rox-containing lines was several orders of magnitude less that that detected in similar samples from the 16A line (see Figs. 1e, 3b). Thus, it remains possible that differences in expression between the 16A-Rox and 14A-Rox lines could not be detected under conditions in which critical regulatory mechanisms were missing and exogenous sequences interfered with robust expression of the human transgene.

Our study serves as a cautionary note for future studies aimed at studying human transgene regulation in the context of the living mouse. Despite taking extensive precautions to ensure that we were comparing the effect of the human variant within the context of an otherwise identical single-copy transgene engineered at the same genomic location, we encountered several problems that led to both ectopic and hypomorphic expression of the human transgene in the mouse brain. This was particularly surprising as the mark left behind after recombineering was upstream of the promoter region. It is worth noting that the area shows a considerable conservation across primates (Supplementary Fig. 3). Nevertheless, using bioinformatic tools we avoided any potential disruption of transcription factor binding or DNAse I hypersensitivity sites using UCSC Genome Browser with the DNase I Hypersensitivity Peak Clusters and Signal, as well as Integrated Regulation Tracks, both from ENCODE (Supplementary Fig. 3). Furthermore, we are not aware of any reports showing transcription binding at this site. However, we were constrained by the need to place the selectable marker close to the modification site so as to avoid crossover during recombinering. The choice of a double selection cassette was initially tried to allow for absolute seamless replacement; however, neither the rpsLTet (Muyrers et al. 1999; Heermann et al. 2008) nor the SacB-Neo/AMP (Muyrers et al. 2000) approaches turned out working in several repeated experiments. This might have been due to inherent issues with the selection systems or a limitation imposed by our target locus in its particular chromosomal location. Therefore, we finally decided to use a strategy with leaving behind a rox site after successful removal of the selection marker. Alternatively, an approach using ssODN donors without selection could have been attempted, as this technique was shown to successfully introduce mutation into BAC genetic structure (Swaminathan et al. 2001). However, based on our negative experience with the double selection procedures, and given the repeat nature of the 16A target locus and of the highly similar landing patches, we feared that such an approach would rather favor degenerate deletions. As advances in human genetics rapidly uncovers putative genetic variants implicated in disease susceptibility and researchers are increasingly seeking to use the mouse as a platform to uncover their molecular and physiological impact, our study suggests that care must be taken to ensure that the human variants are studied within a sufficiently faithful context.

Acknowledgements We thank Olga Ermakova for establishing the RMCE technology in the laboratory and for help with Southern blot analysis, Haydn Prosser for generously sharing reagents prior to publication, and Vladimir Benes (EMBL Genomic Core Facility) for advice and for sequencing the 16A human BAC. This work was supported by funding from EMBL.

Funding Open access funding provided by Research Institute of Molecular Pathology (IMP)/IMBA - Institute of Molecular Biotechnology/Gregor Mendel Institute of Molecular Plant Biology.

Open Access This article is distributed under the terms of the Creative Commons Attribution 4.0 International License (http://creativeco mmons.org/licenses/by/4.0/), which permits unrestricted use, distribution, and reproduction in any medium, provided you give appropriate credit to the original author(s) and the source, provide a link to the Creative Commons license, and indicate if changes were made.

\section{References}

Anastassiadis K, Fu J, Patsch C, Hu S, Weidlich S, Duerschke K, Buchholz F, Edenhofer F, Stewart AF (2009) Dre recombinase, like Cre, is a highly efficient site-specific recombinase in E. coli, mammalian cells and mice. Dis Models Mech 2:508-515

Ansorge MS, Zhou M, Lira A, Hen R, Gingrich JA (2004) Early-life blockade of the 5-HT transporter alters emotional behavior in adult mice. Science 306:879-881

Canli T, Omura K, Haas BW, Fallgatter A, Constable RT, Lesch KP (2005) Beyond affect: a role for genetic variation of the serotonin transporter in neural activation during a cognitive attention task. Proc Natl Acad Sci USA 102:12224-12229

Caspi A, Sugden K, Moffitt TE, Taylor A, Craig IW, Harrington H, McClay J, Mill J, Martin J, Braithwaite A, Poulton R (2003) Influence of life stress on depression: moderation by a polymorphism in the 5- HTT gene. Science 301:386-389

Colucci R, Blandizzi C, Bellini M, Ghisu N, Tonini M, Del Tacca $M(2008)$ The genetics of the serotonin transporter and irritable bowel syndrome. Trends Mol Med 14:295-304

Dannlowski U, Ohrmann P, Bauer J, Kugel H, Baune BT, Hohoff C, Kersting A, Arolt V, Heindel W, Deckert J, Suslow T (2007) Serotonergic genes modulate amygdala activity in major depression. Genes Brain Behav 6:672-676 
Ermakova O, Piszczek L, Luciani L, Cavalli FM, Ferreira T, Farley D, Rizzo S, Paolicelli RC, Al-Banchaabouchi M, Nerlov C, Moriggl R, Luscombe NM, Gross C (2011) Sensitized phenotypic screening identifies gene dosage sensitive region on chromosome 11 that predisposes to disease in mice. EMBO Mol Med 3:50-66

Greenberg BD, Li Q, Lucas FR, Hu S, Sirota LA, Benjamin J, Lesch KP, Hamer D, Murphy DL (2000) Association between the serotonin transporter promoter polymorphism and personality traits in a primarily female population sample. Am J Med Genet 96:202-216

Hariri AR, Holmes A (2006) Genetics of emotional regulation: the role of the serotonin transporter in neural function. Trends Cogn Sci 10:182-191

Heermann R, Zeppenfeld T, Jung K (2008) Simple generation of sitedirected point mutations in the Escherichia coli chromosome using Red(R)/ET(R) Recombination. Microb Cell Factor 7:14

Heils A, Teufel A, Petri S, Stöber G, Riederer P, Bengel D, Lesch KP (1996) Allelic variation of human serotonin transporter gene expression. J Neurochem 66:2621-2624

Heinz A, Braus DF, Smolka MN, Wrase J, Puls I, Hermann D, Klein S, Grüsser SM, Flor H, Schumann G, Mann K, Büchel C (2005) Amygdala-prefrontal coupling depends on a genetic variation of the serotonin transporter. Nat Neurosci 8:20-21

Holst J, Szymczak-Workman AL, Vignali KM, Burton AR, Workman CJ, Vignali DAA (2006) Generation of T-cell receptor retrogenic mice. Nat Protoc 1:406-417

Homberg JR, Schubert D, Gaspar P (2010) New perspectives on the neurodevelopmental effects of SSRIs. Trends Pharmacol Sci 31:60-65

Hranilovic D, Stefulj J, Schwab S, Borrmann-Hassenbach M, Albus M, Jernej B, Wildenauer D (2004) Serotonin transporter promoter and intron 2 polymorphisms: relationship between allelic variants and gene expression. Biol Psychiatry 55:1090-1094

J-eun Oh, Zupan B, Gross S, Toth M (2009) Paradoxical anxiogenic response of juvenile mice to fluoxetine. Neuropsychopharmacology 34:2197-2207

Kaufman J, B-zhu Yang, Douglas-Palumberi H, Houshyar S, Lipschitz D, Krystal JH, Gelernter J (2004) Social supports and serotonin transporter gene moderate depression in maltreated children. Proc Natl Acad Sci USA 101:17316-17321

Kendler KS, Kuhn JW, Vittum J, Prescott CA, Riley B (2005) The interaction of stressful life events and a serotonin transporter polymorphism in the prediction of episodes of major depression: a replication. Arch Gen Psychiatry 62:529-535

Kremers G-J, Goedhart J, van Munster EB, Gadella TWJ (2006) Cyan and yellow super fluorescent proteins with improved brightness, protein folding, and FRET Förster radius. Biochemistry 45:6570-6580

Lau JYF, Goldman D, Buzas B, Fromm SJ, Guyer AE, Hodgkinson C, Monk CS, Nelson EE, P-hong Shen, Pine DS, Ernst M (2009) Amygdala function and 5-HTT gene variants in adolescent anxiety and major depressive disorder. Biol Psychiatry 65:349-355

Lesch KP, Bengel D, Heils A, Sabol SZ, Greenberg BD, Petri S, Benjamin J, Müller CR, Hamer DH, Murphy DL (1996) Association of anxiety-related traits with a polymorphism in the serotonin transporter gene regulatory region. Science 274:1527-1531

Lesch KP, Meyer J, Glatz K, Flügge G, Hinney A, Hebebrand J, Klauck SM, Poustka A, Poustka F, Bengel D, Mössner R, Riederer P, Heils A (1997) "The 5-HT transporter gene-linked polymorphic region (5- HTTLPR) in evolutionary perspective: alternative biallelic variation in rhesus monkeys" Rapid communication. J Neural Transm 104:1259-1266

Lima L, Mata S, Urbina M (2005) Allelic isoforms and decrease in serotonin transporter mRNA in lymphocytes of patients with major depression. NeuroImmunoModulation 12:299-306

Little KY, McLaughlin DP, Zhang L, Livermore CS, Dalack GW, McFinton PR, DelProposto ZS, Hill E, Cassin BJ, Watson SJ,
Cook EH (1998) Cocaine, ethanol, and genotype effects on human midbrain serotonin transporter binding sites and mRNA levels. Am J Psychiatry 155:207-213

Malison RT, Price LH, Berman R, van Dyck CH, Pelton GH, Carpenter L, Sanacora G, Owens MJ, Nemeroff CB, Rajeevan N, Baldwin RM, Seibyl JP, Innis RB, Charney DS (1998) Reduced brain serotonin transporter availability in major depression as measured by [123I]-2 beta-carbomethoxy-3 beta-(4-iodophenyl)tropane and single photon emission computed tomography. Biol Psychiatry 44:1090-1098

Mlinar B, Montalbano A, Piszczek L, Gross C, Corradetti R (2016) Firing properties of genetically identified dorsal raphe serotonergic neurons in brain slices. Front Cell Neurosci 10:195

Munafò MR, Brown SM, Hariri AR (2008) Serotonin transporter (5-HTTLPR) genotype and amygdala activation: a meta-analysis. Biol Psychiatry 63:852-857

Murphy DL, Lerner A, Rudnick G, Lesch K-P (2004) Serotonin transporter: gene, genetic disorders, and pharmacogenetics. Mol Interv 4:109-123

Muyrers JP, Zhang Y, Testa G, Stewart AF (1999) Rapid modification of bacterial artificial chromosomes by ET-recombination. Nucleic Acids Res 15:1555-1557

Muyrers JP, Zhang Y, Benes V, Testa G, Ansorge W, Stewart AF (2000) Point mutation of bacterial artificial chromosomes by ET recombination. EMBO Rep 1:239-243

Nakamura M, Ueno S, Sano A, Tanabe H (2000) The human serotonin transporter gene linked polymorphism (5-HTTLPR) shows ten novel allelic variants. Mol Psychiatry 5:32-38

Noskova T, Pivac N, Nedic G, Kazantseva A, Gaysina D, Faskhutdinova G, Gareeva A, Khalilova Z, Khusnutdinova E, Kovacic DK, Kovacic Z, Jokic M, Seler DM (2008) Ethnic differences in the serotonin transporter polymorphism (5-HTTLPR) in several European populations. Progress Neuropsychopharmacol Biol Psychiatry 32:1735-1739

Parsey RV, Hastings RS, Oquendo MA, Hu X, Goldman D, Y-yu Huang, Simpson N, Arcement J, Huang Y, Ogden RT, Van Heertum RL, Arango V, Mann JJ (2006) Effect of a triallelic functional polymorphism of the serotonin-transporter-linked promoter region on expression of serotonin transporter in the human brain. Am J Psychiatry 163:48-51

Pezawas L, Meyer-Lindenberg A, Drabant EM, Verchinski BA, Munoz KE, Kolachana BS, Egan MF, Mattay VS, Hariri AR, Weinberger DR (2005) 5-HTTLPR polymorphism impacts human cingulate amygdala interactions: a genetic susceptibility mechanism for depression. Nat Neurosci 8:828-834

Popa D, Léna C, Alexandre C, Adrien J (2008) Lasting syndrome of depression produced by reduction in serotonin uptake during postnatal development: evidence from sleep, stress, and behavior. J Neurosci 28:3546-3554

Prosser HM, Rzadzinska AK, Steel KP, Bradley A (2008) Mosaic complementation demonstrates a regulatory role for myosin VIIa in actin dynamics of stereocilia. Mol Cell Biol 28:1702-1712

Purselle DC, Nemeroff CB (2003) Serotonin transporter: a potential substrate in the biology of suicide. Neuropsychopharmacology 28:613-619

Reimold M, Smolka MN, Schumann G, Zimmer A, Wrase J, Mann K, Hu X-Z, Goldman D, Reischl G, Solbach C, Machulla H-J, Bares R, Heinz A (2007) Midbrain serotonin transporter binding potential measured with [11C]DASB is affected by serotonin transporter genotype. J Neural Transm 114:635-639

Risch N, Herrell R, Lehner T, Liang KY, Eaves L, Hoh J, Griem A, Kovacs M, Ott J, Merikangas KR (2009) Interaction between the serotonin transporter gene (5-HTTLPR), stressful life events, and risk of depression: a meta-analysis. JAMA 301:2462-2471

Shioe K, Ichimiya T, Suhara T, Takano A, Sudo Y, Yasuno F, Hirano M, Shinohara M, Kagami M, Okubo Y, Nankai M, Kanba S 
(2003) No association between genotype of the promoter region of serotonin transporter gene and serotonin transporter binding in human brain measured by PET. Synapse 48:184-188

Southern E (2006) Southern blotting. Nat Protoc 1:518-525

Swaminathan S, Ellis HM, Waters LS, Yu D, Lee EC, Court DL, Sharan SK (2001) Rapid engineering of bacterial artificial chromosomes using oligonucleotides. Genesis 29:14-21

Vernimmen D, Marques-Kranc F, Sharpe JA, Sloane-Stanley JA, Wood WG, Wallace HA, Smith AJ, Higgs DR (2009) Chromosome looping at the human alpha-globin locus is mediated via the major upstream regulatory element (HS-40). Blood 114:4253-4260
Wallace HA, Marques-Kranc F, Richardson M, Luna-Crespo F, Sharpe JA, Hughes J, Wood WG, Higgs DR, Smith AJ (2007) Manipulating the mouse genome to engineer precise functional syntenic replacements with human sequence. Cell 128:197-209

Publisher's Note Springer Nature remains neutral with regard to jurisdictional claims in published maps and institutional affiliations. 